\title{
The Change of Language: A Critical Analysis of New Literacies on Twitter and in Educational Context
}

\author{
Zhilong Zhang \\ School of Foreign Languages, Guangdong Polytechnic College, Zhaoqing, China
}

\begin{abstract}
In modern society, there has been a trend that people tend to use effective tool in everyday correspondence. The development of social media network contributes to such situation. Therefore, a study is needed for the new literacies in the current communication of people's daily life. With the aim to help educators better teach students in modern language context, the author adopted the information on Twitter, a widely-used social media network, and analysed it critically in educational context. It is found that the social media network brings both advantages and flaws to the English language. Such trend makes it more convenient for people to convey information but may confuse the readers and discourage them to read, especially aged people.
\end{abstract}

Index Terms —new literacies, Twitter, educational context

\section{INTRODUCTION}

From the new millennium, there has been dramatic change in the way we live and communicate, owing to the development and rise of digital electronic technologies (Castells, 1996, 2000). For instance, blog, twitter, face book, and tumblr provide opportunities for individuals to share life experiences and personal diaries. Texts and messages contribute to a more convenient way for people to communicate with words rather than voice. E-resources and new media allow students from remote areas to get access to cutting-edge knowledge. Computers and internet implement methods for people from different countries to experience cross-culture communication. For sure, most of us are aware of such technical revolution that changes the way we work, communicate, and entertain (Kellner, 2000). We begin to think differently and formulate new perspectives and opinions about life and the world, our mindset. As a result, "a new kind of mindset has begun to emerge and some new kinds of literacies have begun to evolve" (Lankshear and Knobel, 2006, p. 30). In terms of a more convenient communicative approach, some words can be used with shorter forms, which often come with vowel-free abbreviations and acronyms, when people use in text messaging. An obvious example can be "txt", abbreviated from text (Kleinman, 2010). Some words can be used in a new way. I often hear people use "to google something" in everyday life, which refers to look something up on a search engine. Some acronyms appeared in internet language, such as, "LOL", "ASAP", "DBA" and so forth. These new linguistic aspects provide us with a simpler method to respond and reply on text messaging and the Internet.

Despite the fact that new technologies undoubtedly create more convenient approaches for people's everyday practices, a number of scholars, however, reported great concerns that the change of language might ruin the academic world. Dyson (1997) and Gee (2004) demonstrated worries according to the aspect of educational reform and government authority in that the new forms of language could simplify and reduce public and professional conceptions of literacy. In a recent action research by Hagood (2012), teachers who participated in that study were reported to be uncomfortable about new literacies used in classroom discourse. Students, especially teenagers, are likely to mix words in academic context with those on the Internet, which contributes to a more challenging circumstance in their academic reading and writing practices (Kress, 2003).

Therefore, as a language teacher, it is important for me to comprehend this phenomenon and deal with the challenges. In this paper, I mainly investigate the following aspects:

1. What is the meaning of new literacies?

2. How do the new forms of language influence our everyday practices?

3. How can educators deal with such change in an academic context?

I argue that teacher should utilise the change of language in class but be aware to explain the differences between new language in everyday and academic practices. My opinion is that educators should take a critical view on new forms of language and new types of literacies should be utilised according to the demands of the new millennium in order to connect education to the changing world.

\section{NEW LITERACIES}


The term New Literacies stems from Literacy, which, generally speaking, refers to the ability to read and write. To achieve a better understanding of New Literacies, it is necessary to investigate the meanings of Literacy. Titmus (1989) thinks a literate person should have the knowledge and skills that qualified him in reading and writing, and enabled him to use those skills in his group and community. In other words, literacy is not merely related to the ability of reading and writing a particular kind of script (Lankshear and Knobel, 2007). In addition, it largely includes "socially developed and patterned ways of using technology and knowledge to accomplish tasks" (Scribner and Cole, 1981, p. 236). I completely appreciate the social approach of comprehending the meanings of literacy and as far as I am concerned, literacy is a socially-constructed system of using language. Lankshear and Knobel (2006a) regard literacy as "socially recognized ways of generating, communicating and negotiating meaningful content through the medium of encoded texts within contexts of participation in Discourses" (p. 64). McCaffery et al. (2007) defined this term as "a set of social and cultural practices linked by the use of the written word, and a tool for critical reflection and action for social change" (p. 35). A reason definition of literacy can be traced to UNESCO (2012).

"Literacy is the ability to identify, understand, interpret, create, communicate and compute, using printed and written materials associated with varying contexts, which involves a continuum of learning in enabling individuals to achieve their goals, to develop their knowledge and potential, and to participate fully in their community and wider society. "UNESCO $(2012, p$. 5)

Regarding the above perspectives, it can be concluded that literacy refers to the competence of utilising language in certain social context to achieve communication. Since it is related to social activities to a great extent, the change of life styles in a society more or less influences the way, in which we use language.

Having comprehended the meanings of literacy, it is appropriate to study "New Literacies". As part of social practice, the forms of language are largely regulated by the continuous social change and the technologies (Boyarin, 1993; Gee, 1996; Manguel, 1996). In contemporary society, the growth of new technologies places a huge demand on language in communication. It is easily to find that people redefine literacy or attach new meanings to linguistic aspects when using electronic devices, like website (Kinzer, 2003; Lewis and Fabos, 1999). To utilise the linguistic functions of inferring special ideas, like limited time or amusement, people feel the need to modify the language they use to some new kinds of literacies (Coiro, 2003; Kinzer and Leander, 2003; Lankshear and Knobel, 2003; Leu, 2000a; Smolin and Lawless, 2003).

To understsnd the meanings of new literacies, however, is not simply an unproblematic approach. Leu et al. (2004) pointed out two major difficulties when defining new literacies: there existed very little research on new literacies; scholars lack a precise definition of new literacies. Though I more or less disagree with the latter, I have to admit that few studies have been done on this field in that new technologies appear significantly fast. I understand the reasons why researchers, like Leu et al. placed a strong need for a precise definition. They want a framework of "theory development as well as systematic investigation" in order to form a clear concept about new literacies (Leu, et al., 2004, p. 2). However, one aspect we need to know is that language is not set in stone, so as definition. It changes with the times. Apart from requesting a precise definition, why don't we take a look at the major element (technology) of the terminology?

From the very beginning, literacy was connected to the available means of technology, namely, "oral sounds, drums and flutes, gestures, facial expressions, petroglyphs, or the display of artifacts" (Bruce, 2003, p. 15). Since the invention of the Internet, new forms of literacy appeared, which affected people's everyday practices of literacy. Those who used to read with books in the past are now used to reading e-materials, proved by Lenhart, Simon, and Graziano (2001) who discovered that the younger generations in the United States depended on e-recourses for study to a great extent. In other words, new literacies are largely influenced by technologies. Some scholars, like Hagood (2012) agreed with this aspect and contributed to some interesting definitions. One representative definition is that "new Literacies are digital literacies; online, messaging, sms, phones and computers" (New Literacies \& Classroom Practice, 2005, p. 1). This definition regards new literacies as digital means of using language. The technical component of new literacies cannot be denied, but is it merely about technology?

In my opinion, the answer obviously is "no". As I put forward at the beginning, literacy is largely related to social practices. An appropriate way to define new literacies is to combine social practices with technologies. In agreement with Leu et al. (2007), four categories have been listed to define new literacies.

1. New technologies require new linguistic knowledge and skills;

2. New literacies contribute to cross-culture communication and global society;

3. New literacies change regularly according to the change of technologies;

4. New literacies include multiple views towards comprehension.

It can be seen from these categories that new literacies are an inclusive concept, involving new technologies, communication, and views.

Though all the above components are relevant to new literacies, in this essay, however, the author mainly adopts the linguistic aspect of new literacies in contemplation of investigating the linguistic change. Lankshear and Knobel (2006) raised another definition, differentiated from the above definitions, that is, "new socially recognized ways of generating, communicating and negotiating meaningful content through the medium of encoded texts within contexts of 
participation in Discourses" (p. 65). This definition emphasises the social way to generate text in certain context, which is about language change according to people's everyday practices.

Combining the previous research and my interests in language change, I define new literacies as new ways to generate meaningful content to achieve communication in certain contexts, modified by new technologies and "pop culture" (Hagood, 2012, p. 10), which place differences compared to the conventionally recognised ways to use language.

\section{TyPiCAL FEATURES OF NEW LITERACIES ON TwitTER}

Nowadays, new technologies grow significantly fast and influence the language that people use accordingly. To investigate the modern language, it is necessary to study some concrete prevalent linguistic aspects. In this part, this essay analysed some current and popular examples in a worldwide blog, twitter, to take a closer look at how up-to-date language is used. The author adopted the tweets on Twitter, a worldwide blog that allows people to share information with limited words but various forms.

\section{A. The Replacement of Word}

On Twitter, people sometimes use different styles to post their tweet by replacing the words with various forms. Some numbers are used currently to take the place of letters, owing to their similar pronunciations. The Twitter only allows "our most sophisticated thoughts and feelings into a measly 140 characters (or less)" (Hockenson, 2012, p. 1). Therefore, another function of number replacement is to save space to express complete idea, which is adopted in some celebrities' tweets.

a. Some1 just said if u drink red wine everyday U'LL b more beautiful. Naturally blushed cheeks \& relaxed facial expression. (Tyra Banks, 2015, Mar. 3)

b. So grateful 2 be included among the greatest comic talent of the last 4 gens on SNL 40th anniversary and 2 all of $u 4$ putting me there. ;^) (Jim Carrey, 2015, Feb. 16)

c. come 2night \& see new exhibition, one of my FAV ARTISTS \#waelshawkyw/@klausbiesenbach @ momaps1 amazing marionettes! (Lady Gaga, 2015, Jan. 31)

The above cases represent some situations where number replaces letter. In (a), Tyra Banks used 1 after "some" to express the word "someone", which combines letters and numbers to form a word that is commonly used. This act changes the conventionally recognised word forms to newly forms but not recognised structures. Similar examples can be seen in Netlingo, where chat acronyms and text shorthand are collected and listed. In (c), as well, Lady Gaga used 2 to represent "to" in the spelling of "tonight". The newly formed word "2night" seems to be more prevalent than "some1" in that I received a number of messages where "2night" appeared in the text. Likewise, a more widely used form is number replacing the whole word rather than parts of it. In (b), Jim Carrey described his thankfulness to his fans. He adopted "2" and " 4 " to replace "to" and "for". This adoption, however, may lead to misunderstanding of his expression for those are not familiar with the use of number in internet language. It can be seen from these examples that there are two major trends of using number in new literacies practices: the combination of figure and letter, and the replacement of number and word. Through the observation of over 500 tweets among different individuals in Twitter, the trend of using number is still in a traditional manner, which replaces the word form of number with figure, like four and 4.

Besides numbers, some letters also replace words. A very typical example can be " $U$ ". The pronunciation of " $U$ " is the same as "you". For the purpose of convenience, Tyra Banks in (a) used "U" and "U'LL" instead of "you" and "you'll". This expression is widely accepted on Twitter and can widely be seen in people's messages and notes.

\section{B. Sign and Picture}

A very interesting expression on Twitter is the use of pictures and signs to cover the meanings of words. Some signs have typical meanings in internet language, like @ and \#.

d. Thank you dear friend @ KarlLagerfeld for photographing me and my stylist @ Brandonvmaxwell Fashion is love! (Lady Gaga, 2015, Mar. 19)

e. Get the champagne! The show was a HIT! Kate and Gaga • Wang at Balenciaga!! (Lady Gaga, 2015, Mar. 6)

f. Chris is joining @GlblCtzn in their campaign to end extreme poverty by 2030. Please sign up with him http://bit.ly/glblctzn \#GlobalCitizen (Coldplay, 2015, Feb. 13) g. Mornin' (Tyra Banks, 2015, Mar. 13)

The sign @ is considered as the most important aspect on Twitter, without which people are not able to communicate (Hockenson, 2012). It is the "necessary marker for the system to recognise when you're talking to someone and therefore alert them of the mention" (Hockenson, 2012, p. 1). With this sign, individuals feel it easier to contact people and seek reply. For example, in (d), Lady Gaga used the symbol "@" to send her thankfulness to her friend KarlLagerfeld and tell her stylist Brandonvmaxwell about her passion of fashion. By using "@”, her friends can see what Lady Gaga writes on Twitter immediately, owing to the alert of the Twitter's system. It plays an important role in people's requirement of easy and quick communication and interaction on Twitter. Similarly, another significant 
symbol is "\#", which expresses the meaning of "topic". By showing the topic of a tweet, this hashtag implies a current event. Therefore, it refers to "topic" and "current tendency". In (f), Coldplay persuaded the fans to take part in the campaign to end poverty and used "\#" to connect the expression to a current programme, GlobalCitizen. By demonstrating the idea clearly, the fans are able to recognise the content of GlobalCitizen, which helps Coldplay to achieve their goal. Some oral expressions are also used on Twitter. In oral English, some people tend to weaken the sound of "ing" when speaking. This phenomenon now appears on Twitter, like (f). Unlike the typical form of "morning", Tyra Banks used the oral expression "mornin"”. It can be seen that oral English affects people's literacy practices.

Instead of expressing the whole ideas with phrases and sentences, people sometimes use pictures to describe their feelings. Like $\$$ in (e), it infers the meaning of "like" and "love". Lady Gaga used this to show her love and appreciation of Wang. However, pictures may result in misunderstanding. Without words, the viewers have to guess the meaning according to their own experiences and opinions. Although pictures can add vividness to the tweets, they also create obstacles for people to achieve comprehension.

\section{The Change of Words}

Besides the use of numbers and signs, another tendency is the change of words, obvious examples of which are abbreviation and initial. The former (also called clipping) refers to "a process that shortens a polysyllabic word by deleting one or more syllables" (O'Grady et al., 2001, p. 157), whereas the latter (also called acronyms) means "taking the initial letter of (some or all) the words in a phrase or title and pronouncing them as a word" (O'Grady et al., 2013, p. 137).

The use of abbreviations of English language stemmed from the fifteenth century, when the "early forms of dictionaries of initialisms" appeared (Cannon, 1989, p. 99). A main reason why people tend to use shorter form of word and phrase is that it helps save time and labour. Therefore, it is "convenience and sometimes a temptation" (Cannon, 1989, p. 103). Through the frequent practices of abbreviation, some words have been modified to a shorter form and widely recognised, like "exam" and "examination", "photo" and "photograph" (Cambridge Dictionaries Online, 2015). Language on Twitter meets such change as well.

h. @ Helix: RT if you can't wait to swoon over Sergio in tonight's all-new episode of \#Helix at 10/9c. ”

Crockett! (Steven Adelson, 2015, Mar. 20)

i. My bro killed that shiiiittt! \#Ultra lets GOOO JB! (Justin Bieber, 2015, Mar. 29)

j. Lol. \#BieberRoast (Justin Bieber, 2015, Mar. 30)

RT refers to retweet, "an action on tweeting where someone broadcasts the message of another person they are following" (Hockenson, 2012, p. 2). This acronym has the function of replying and requesting. In (h), for instance, Steven Adelson used RT to make a request to his fans that attracts their attention to the new episode. RT is unique on Twitter in that it reflects the communicative function of Twitter system. In addition to "RT", LOL is accepted in everyday speaking and also used on Twitter, like (j). The prevalent meaning of "LOL" is laughing out loud (Morgan, 2011). And it is used in everyday communication to express joke, amusement, and humorous statement. People often say this phrase as a word to begin a conversation with friends. "Bro", the shorter form of "brother" is also widely accepted in everyday language. It does not merely refer to "brother" as relative, but can also be used among close friends, especially by boys.

\section{Summary}

It can be seen from the above features that new literacies on Twitter have multiple forms, such as number expression, letter replacement, sign and visual expression, and the different adoption of word and phrase forms. The various forms of language demonstrate its animation and vividness, which help prosper the language. Through the analysis of the above tweets, the author found that people had personal and individual preference of using new literacies, probably as everyday language. In addition, everyday language practices largely affect people's adoption of new literacies on Twitter. In certain discourse, the new literacies convey concrete meanings. However, people outside the discourse may not be able to comprehend the tweets clearly. In this manner, new literacies create obstacles for viewers to peruse successful understanding. As a result, new literacies on Twitter may still not be accepted by the majority of people.

\section{DISCUSSION}

Compared to new literacies on Twitter that focus on individuals' everyday language practices, the literacy in educational context consists of three main differences: literacy in educational context is largely taught by teachers in schools; it is conventionally formed and recognised by the majority of people; it relates to "the use of dominant language" (McCaffrey et al., 2007, p. 126) and accepted as national and official language (UNESCO, 2005a). Some literacy teachers think highly of new literacies in classroom teaching and learning out of the reason that the new forms of language contribute to learners' better understanding of "real-world skills and exhibit personal growth" (Kist, 2004, p. 3), whereas some disagree with such idea and place negative opinions of new literacies in that the change of language may break the "original standard" (Aitchison, 2000, p. 120) and lead to some side effects (Bruce, 2003). The new form of language is actually the challenge of tradition. With critical perspectives, a number of researchers consider this 
situation as a double-edge sword (Baker and O'Neil, 1994; Roblyer, Castine and King, 1988). In agreement with the objective and critical approach of these researchers, the essay views that new literacies could break the traditionally formed language and cause trouble, but educators should have a critical point of view towards such language change and utilise it in educational context.

The spread of new literacies may result in troubles. The new forms of language people use on Twitter keep challenging their traditional knowledge. A major difference between them is the way in which people acquire knowledge. Generally speaking, there is little systematic education of new literacies, especially the analysis of online reading comprehension (Coiro and Dobler, 2007). Individuals, in most cases, learn the way to use these skills through their everyday practices, which, largely depends on their original literacy skills. However, "little is known about how to analyze or teach those skills" (Leu et al., 2007, p. 39). Without systematic study, they are not able to use the new language as well as the traditionally formed language. According to the examples of the above celebrities, people have preferable choice of language and expressions, which, sometimes, cause misunderstanding to those outside the discourse. Unlike new literacies, traditional literacy is generally acquired by people from schools and everyday practices, which help them found an overall and background knowledge of the prevalent language and contribute to their mutual understanding owing to that fact that the literacy their acquire is publicly recognised and systematically studied. People are taught with dominant language. On the Internet, the abuse of new literacies, however, creates obstacle for people to read, especially the older generation. Currently, most students do not receive support when developing new literacies skills in online reading comprehension (Leu, 2006). These students, however, depend largely on the Internet for resources for the Internet becomes a central source of information (Lyman and Varian, 2003).Therefore, new literacies actually discourage people to read on the Internet and contribute to people's online reading difficulty.

Another flaw of new literacies is the misuse of language. Language has different functions in context. In some important context like speeches and interviews, individuals are supposed to use formal language in order to demonstrate their ability of academic status and impress the audience. Generally speaking, there are a few situations that require people to use formal language:

When writing an essay for a class.

When writing an email for work that's going to go out to a lot of people in the company who you don't personally know.

When speaking to a customer who you don't know on a first-name basis.

When speaking with someone who's a lot older than you.

(PhraseMix, 2015, p. 1)

Writing in educational often requires students to use formal English so as to equip those students with literacy skills in their future career. To show respect to the older generation and people with high status, individuals are supposed to utilise formal English. Nevertheless, the spread of new literacies on the Internet often leads to the mix of languages from different contexts. Through the analysis of Twitter language, the author found that new literacies were closely related to peoples' everyday language. People are likely to write with everyday language, proved by the analysis of tweets. As a result, teachers may find it more difficult to improve students' academic writing ability.

Despite the fact that new literacies place great challenge in the educational context, it can not be denied that the new literacies have some advantages. Firstly, new literacies contribute to the diversity and variety of English that stop English from dying out. The phenomenon of language dying out does not refer to the alter of language over centuries, but means the total disappearance of a language (Aitchison, 2000). The appliance of new literacies combines people's everyday language practices with the new technology to create new forms of language that can be used for individuals to catch up with the times. This is an effective way to demonstrate the liveliness of language. With multiple forms of expressions, people are able to build up personal and individual styles when writing on Twitter. Additionally, the contemporary society increasingly requires people to ustilse new literacies skills. The Internet, nowadays, frequently appears in the workplace, in which the staff must possess certain skills and strategies during online reading (Coiro and Dobler, 2007). Those knowledge and skills include the components of traditional literacy and new literacies. Coiro and Dobler (2007) also found a number of connections between online reading comprehension and offline reading understanding. That is to say, it may be ignorant to neglect the functions and skills of new literacies in the new millennium.

\section{CONCLUSION}

This essay considered new literacies as a social approach to language change according to new technologies and new ways to generate meaningful content to achieve communication in certain contexts. With a critical analysis of new literacies on Twitter, the author found the major advantages and flaws.

On the one hand, new literacies place great challenge on the conventionally formed language in the educational context, where formal language is taught. Literacy education equips students with socially recognised and systematic skills of reading and writing through classroom teaching and everyday learning. New literacies, however, mainly focus on students' everyday practices and so far there is little systematic education guide about those new languages. As a result, people adopt their preferable new aspects of language in online reading and writing, which have not been 
publicly recognised. This phenomenon in fact may confuse the readers and discourage them to continue reading. Also, the fact that new literacies are more prevalent in the younger generations, aged people may not understand the change, which strengthens the generation gap.

On the other hand, new literacies serve people's requirement for convenient communication in the new millennium. In the modern society, an easy and fast approach of communication has become a trend of individuals' everyday practices. Some companies place great emphasis on employees' new skills and strategies to online reading comprehension (Leu et al., 2007), which has been a major source of information since the new millennium when computers and the Internet were put to use and spread all over the world. The skills and strategies of new literacies actually equip the next generation with better literacy ability to keep pace with the times and the social tendency.

\section{Implications}

There exist both positive and negative views on such change of language. Neither view may not be appropriate for educators in the society with increasing new technologies and modern culture. Teachers are supposed to take a critical perspective of new literacies and make good use of those skills and strategies in the educational context. Through the study of the current situation of new literacies, the author has summed up with some recommendations for educators.

1. Teachers should recognise the communicative approach of new literacies but remember to help students distinguish the useful forms of language in different context.

2. Formal language teaching is still appropriate in the current literacy education, which contributes to students' future development.

3. Online reading support should be given to students.

\section{REFERENCES}

[1] Aitchison, J. (2000). Language Change: Progress or Decay? United Kingdom: Cambridge University Press.

[2] Bruce, B. C. (2003) Literacy in the information age: inquiries into meaning making with new technologies. Newark, Del.: International Reading Association.

[3] Boyarin, J. (eds.). (1993). The ethnography of reading. Berkeley: University of California Press.

[4] Cambridge Dictionaries Online. (2015). Abbreviations, initials and acronyms from English Grammar Today, from http://dictionary.cambridge.org/grammar/british-grammar/abbreviations-initials-and-acronyms (accessed 29/3/2015).

[5] Cannon, G. (1989). Abbreviations and Acronyms in English Word-Formation. American Speech, 64(2), 99-127.

[6] Castells, M. (1996). The Rise of the Network Society. Oxford: Blackwell.

[7] Castells, M. (2000). The Rise of the Network Society. 2nd edn. Oxford: Blackwell.

[8] Coiro, J., and Dobler, E. (2007). Exploring the online reading comprehension strategies used by sixth-grade skilled readers to search for and locate information on the Internet. Reading Research Quarterly, 42(2), 214-57.

[9] Coiro, J. (2003). Reading comprehension on the Internet: Expanding our understanding of reading comprehension to encompass new literacies. The Reading Teacher, 56(5), 458-464.

[10] Dyson, A.H. (1997). Writing Superheroes: Contemporary Childhood, Popular Culture and Classroom Literacy. New York: Teachers College Press.

[11] Gee, J.P. (1996). Social linguistics and literacies: Ideology in discourses. London: Taylor \& Francis.

[12] Gee, J.P. (2004). Situated Language and Literacy: A Critique of Traditional Schooling. London: Routledge.

[13] Hagood, M. C. (2012). Risks, Rewards, and Responsibilities of Using New Literacies in Middle Grades. Voices from the Middle, 19(4), 10-16.

[14] Kellner, D. (2000). New Technologies/New Literacies: reconstructing education for the new millennium. Teaching Education, 11(3), 245-265.

[15] Kleinman, Z. (2010). How the internet is changing language. http://www.bbc.co.uk/news/technology-10971949 (accessed 29/3/2015).

[16] Kress, G. (2003). Literacy in the New Media Age (Literacies). United Kingdom: Routledge.

[17] Kinzer, C.K. (2003). The importance of recognizing the expanding boundaries of literacy. http://www.readingonline.org/electronic/elec_index.asp?HREF=/electronic/kinzer/index.html (accessed 20/3/2015).

[18] Kinzer, C.K., \& Leander, K. (2003). Technology and the language arts: Implications of an expanded definition of literacy. In J. Flood, D. Lapp, J.R. Squire, \& J.M. Jensen (Eds.), Handbook of research on teaching the English language arts. Mahwah, NJ: Erlbaum, 546-566.

[19] Kist, W. (2004). The New Literacies Movement: Reading and Writing in the Digital Age. http://www.nais.org/MagazinesNewsletters/ISMagazine/Pages/The-New-Literacies-Movement.aspx (accessed 11/4/2015).

[20] Lankshear, C. and Knobel, M. (2006). New literacies: Everyday practices \& classroom learning. New York: Open University Press and McGraw Hill.

[21] Lankshear, C. and Knobel, M. (2007). Researching New Literacies:Web 2.0 Practices and Insider Perspectives. E-Learning and Digital Media, 4(3), 224-240.

[22] Lenhart, A., Simon, M. and Graziano, M. (2001). The Internet and Education. http://www.pewinternet.org/2001/09/01/theinternet-and-education/ (accessed 15/4/2015).

[23] Leu, D. J., Zawilinski, L., Castek, J., Banerjee, M., Housand, B. C., Liu, Y. and O’Neil, M. (2007). What Is New About The New Literacies of Online Reading Comprehension? In: Rush, L. S., Eakle, A. J. and Berger, A. (Eds.) Secondary School Literacy: What Research Reveals for Classroom Practice. Urbana, IL: National Council of Teachers of English, 37-68.

[24] Leu, D.J., Jr. (2000a). Literacy and technology: Deictic consequences for literacy education in an information age. In M.L. Kamil, P.B. Mosenthal, P.D. Pearson, \& R. Barr (Eds.). Handbook of reading research. Mahwah, NJ: Erlbaum, 743-770. 
[25] Lewis, C., \& Fabos, B. (1999). Chatting on-line: Uses of Instant Messenger among adolescent girls. Paper presented at the annual meeting of the National Reading Conference, Orlando, FL.

[26] Manguel, A. (1996). A history of reading. New York: Viking.

[27] McCaffrey, J., Merrifield, J. and Millican, J. (2007). Developing Adult Literacy: Approaches to Planning, Implementing and Delivering Literacy Initiatives. United Kingdom: Oxfam Professional.

[28] Morgan, J. Why did LOL infiltrate the language? http://www.bbc.co.uk/news/magazine-12893416 (accessed 11/4/2015).

[29] O'Grady, W., Archibald, J., Aronoff, M. and Rees-Miller, J. (2013). Contemporary Linguistics: An Introduction (Learning about Language Series). Boston: Bedford, St. Martin's.

[30] O'Grady, W., Dobrovolsky, M. and Katamba, F. (2001). Contemporary Linguistics: An Introduction (Learning about Language Series). United Kingdom: Person ESL.

[31] Scribner, S. and Cole, M. (1981).The Psychology of Literacy. Cambridge, MA: Harvard University Press.

[32] Smolin, L.I., \& Lawless, K.A. (2003). Becoming literate in the technological age: New responsibilities and tools for teachers. The Reading Teacher, 56(6), 570-577.

[33] Titmus C.J. (1989). Lifelong education for adults. An international handbook. Oxford: Pergamon Press.

[34] UNESCO (2005a). 'Literacy for Life 2006', Education for All Global Monitoring Report. Paris: UNESCO.

[35] UNESCO (2012). Functional Literacy in Eastern and Western Europe. United Kingdom: UNESCO Institute for Education.

Zhilong Zhang was born in Zhaoqing, China in 1990. He received his master's degree from the University of Bolton, UK in 2015. $\mathrm{He}$ is currently a teacher in the School of Foreign Languages, Guangdong Polytechnic College, Zhaoqing, China. His research interests include cross-cultural teaching and discourse analysis. 